\title{
Re: Criteria to Choose Between Distal or Proximal Venous Port Device Insertion in HNC Patients
}

\author{
Akio Akahane $\cdot$ Miyuki Sone $\cdot$ Shigeru Ehara
}

Received: 11 April 2012/ Accepted: 17 April 2012/Published online: 8 June 2012

(C) Springer Science+Business Media, LLC and the Cardiovascular and Interventional Radiological Society of Europe (CIRSE) 2012

We thank Dr. Marcy et al. [1] for his interest in our paper entitled "Subclavian vein versus arm vein for totally implantable central venous port for patients with head and neck cancer: a retrospective comparative analysis [2]" and we appreciate this opportunity to make a comment on his letter.

In our study, we compared two different routes of venous access, the subclavian and arm veins, for patients with head and neck cancer (HNC). Incidence of postprocedural adverse events was significantly higher in the arm port group $(8.5 \%)$ than in the subclavian port group (22.6\%) [2]. Phlebitis was the most frequently encountered events in our study and it is seen only in patients with an arm port $(9.5 \%)$. Kuriakose et al. [3] observed a significant difference between the rate of venous thrombosis in the brachial approach $(11.8 \%)$ and that in the subclavicular approach (5.2\%). Because mechanical stress on the catheter may lead to phlebitis or upper extremity thrombosis, the length of catheter, the ratio of dimensions of the implanted catheter and the target vein, and venous stasis are included in the potential causative factors. Allen et al. [4] demonstrated that phlebitis occurred less often in basilic vein approach than in cephalic vein approach. It is the limitation of our study, because we did not analyze these factors.

\footnotetext{
A. Akahane - M. Sone - S. Ehara

Department of Radiology, Iwate Medical University School of Medicine, 19-1 Uchimaru, Morioka 020-8505, Japan

Present Address:

A. Akahane $(\square)$

Care-Plaza Otsuchi, 14-82-1, Kozuchi, Otsuchi-cho

Kamihei-gun, Iwate 028-1121, Japan

e-mail: a.akahane@gmail.com

M. Sone

Department of Diagnostic Radiology, National Cancer Center Hospital, 5-1-1, Tsukiji, Chuo-ku, Tokyo 104-0045, Japan
}

The systemic chemotherapy for HNC consisting of docetaxel, cisplatinum, and 5-fluorouracil is commonly performed [5], and the central venous ports will be indicated in HNC patients more frequently in the future. Criteria for port selection in HNC patients may become an important guide to treat such patients. Although our experiences are still limited, we all agree with the selection criteria described in the letter [1]. We believe that we will find the most reasonable approach based on the author's proposal with further experience.

Conflict of interest The authors declare that they have no conflict of interest.

\section{References}

1. Marcy et al (2011) Criteria to choose between distal or proximal venous port device insertion in HNC patients. Cardiovasc Intervent Radiol 34:1222-1229

2. Akahane A, Sone M, Ehara S, Kato K, Tanaka R, Nakasato T (2011) Subclavian vein versus arm vein for totally implantable central venous port for patients with head and neck cancer: a retrospective comparative analysis. Cardiovasc Intervent Radiol 34(6):1222-1229

3. Kuriakose P, Colon-Otero G, Paz-Fumagalli R (2002) Risk of deep venous thrombosis associated with chest versus arm central venous subcutaneous port catheters: a 5-year single-institution retrospective study. J Vasc Interv Radiol 13(2 Pt 1):179-184

4. Allen AW, Megargell JL, Brown DB, Lynch FC, Singh H, Singh Y, Waybill PN (2000) Venous thrombosis associated with the placement of peripherally inserted central catheters. J Vasc Interv Radiol 11(10):1309-1314

5. Lorch JH, Goloubeva O, Haddad RI, Cullen K, Sarlis N, Tishler R, Tan $M$ et al (2011) Induction chemotherapy with cisplatin and fluorouracil alone or in combination with docetaxel in locally advanced squamous-cell cancer of the head and neck: long-term results of the TAX 324 randomised phase 3 trial. Lancet Oncol 12(2):153-159 